\title{
An unusual case of myopic shift post acquired brain injury
}

\author{
BY FARRAH F. SUNDERJI, OD \& \\ CATHERINE HEYMAN, OD, FAAO, \\ FCOVD
}

\section{Background}

Ton the United States, approx-
imately one person every 16
seconds suffers some form of ac-
quired brain injury (ABI). ${ }^{1}$ An ABI
results from an event that occurs
suddenly and results in neurologi-
cal dysfunctions. ${ }^{2}$ The two major
events that cause an ABI include
an internal insult such as a cerebro-
vascular accident (CVA), brain

surgery and brain tumours; or a traumatic brain injury (TBI) resulting from an external insult (Table 1). ${ }^{3,4}$ Males are more at risk for both a CVA and TBI. Using Table 1 for classification purposes, this case report illustrates an unusual presentation of myopic shift post ABI due to the presence of multiple brain tumours, brain surgery for removal of the tumours, shunt placement for hydrocephalus, and a CVA post-surgery.

Ocular and visual problems are frequent consequences of an ABI. Cohen ${ }^{1}$ explains that following a
Farrah F. Sunderji, O.D.

Resident, Pediatric Optometry and Vision Therapy

Southern California College of Optometry

2006-2007

Catherine Heyman, O.D., F.A.A.O, FCOVD

Southern California College of Optometry

Faculty Advisor

In memory of the late Michael Rouse, $O D$

\section{RÉSUMÉ}

\section{UN CAS INHABITUEL D'ÉCART MYOPIQUE SURVENANT À LA SUITE D’UNE LÉSION CÉRÉBRALE ACQUISE}

\begin{abstract}
Contexte
Des problèmes oculovisuels surviennent fréquemment après une lésion cérébrale acquise (LCA). Une revue de la documentation révèle que bon nombre de patients présentent un déplacement myopique de l'erreur de réfraction après un traumatisme cérébral, qui est une forme de LCA. Trois formes d'évolution sont présentées. Le plus souvent, la myopie se résorbe sous cycloplégie. En deuxième lieu, le déplacement peut être temporaire et, en troisième lieu, cas le moins courant, la myopie augmente avec le temps. Le présent rapport de cas, même sil n'est pas attribuable à un traumatisme cérébral, est un exemple du cas le moins courant.
\end{abstract}

\section{Rapport de cas}

Le patient, un homme de 63 ans, a subi, 15 mois avant sa première évaluation, l'excision d'une tumeur dans le lobe temporal frontal droit. Il a reçu avant et après l'intervention 4 mg QD qui a fait fluctuer son taux de glucose sanguin entre 5,72 et $22,2 \mathrm{mmol} / \mathrm{L}$; le patient a fait un AVC après l'intervention, ce qui a causé une hémiparésie du côté gauche; un shunt a été posé pour diminuer l'enflure dans la région de l'excision et dans les nerfs optiques. Liste des médicaments : Cartia, lisinopril, Toprol $\mathrm{XL}$, prednisone, Reglan et Temodar. Le patient a fait l'objet d'une chimiothérapie pour traiter les restes de la tumeur. Son dernier examen visuel en 2004 indiquait une erreur de réfraction de -2,50-1,25×080 dans son œil droit et de -3,00-0,75×080 dans son œil gauche avec acuité visuelle de 6/7,5 dans les deux yeux. II s'est présenté à notre clinique avec une acuité visuelle assistée de 8/100 (6/110) dans les deux yeux et une hémianopsie homonyme gauche après évaluation de la périmétrie par comptage des doigts. Une rétinoscopie sous cycloplégie a révélé -6,00-3,00×090 dans son œil droit et -6,00-2,00×090 dans son œil gauche. Un examen du fond d'œil sous pupille dilatée a indiqué une légère enflure des deux nerfs optiques. Les taux de glucose sanguin ont varié entre 103 et 140.
Lors d'une visite de suivi un mois plus tard, sa meilleure acuité visuelle corrigée à une distance s'était améliorée à $6 / 60$ dans les deux yeux grâce à la nouvelle prescription. Sa rétinoscopie sous cycloplégie n'a présenté aucune variation de la myopie ou de l'astigmatisme, toutefois, l'œdème du disque s'est résorbé.

\section{Conclusion}

Ce cas illustre une présentation inhabituelle d'un déplacement myopique à la suite d'une lésion cérébrale acquise. L'état du patient n'a cessé de se détériorer, et celui-ci n'y a pas survécu. On ne sait pas si la myopie et l'astigmatisme ont pris de l'ampleur ou s'ils se sont stabilisés. Même si la cause de cet état n'est pas pleinement comprise et qu'elle nécessite d'autres examens, une correction optique appropriée a toutefois permis d'améliorer la qualité de vie du patient.

Mots clés : tumeurs, traitement de la myopie, lésion cérébrale. 


\section{ABSTRACT}

\section{Background}

Ocular and visual problems are frequent consequences of an acquired brain injury (ABI). The literature suggests that many patients demonstrate a myopic shift in refractive error after a traumatic brain injury (TBI), a form of an ABI. Three reported courses are suggested. Most commonly the myopia resolves under cycloplegic conditions, secondly the shift is transient, and least commonly the myopia increases over time. This case report, although not due to a $\mathrm{TBI}$, is an example of the least common subgroup.

\section{Case Report}

The patient, a 63 year-old male, presented with a history (15 months prior to initial evaluation) of an excised right frontal temporal lobe tumour. The history included dexamethasone 4mg QD preand post-surgery which caused blood glucose levels to fluctuate between
5.72-22.2 mmol//; a stroke occured postsurgery causing hemiparesis on his left side; and shunt surgery to decrease swelling to the area of excision and the optic nerves. Medications included: Cartia, lisinopril, Toprol XL, prednisone, Reglan, and Temodar. The patient was receiving chemotherapy to treat remnants of the tumour. His last eye exam in 2004 indicated a refractive error of $-2.50-1.25 \times 080$ in his right eye and $-3.00-$ $0.75 \times 080$ in his left eye with visual acuity of 6/7.5 in both the right and left eye. He presented to our clinic with an aided visual acuity of $8 / 100(6 / 110)$ in both the right and left eye and a left homonymous hemianopsia on finger counting fields. Cycloplegic retinoscopy revealed $-6.00-$ $3.00 \times 090$ in his right eye and -6.00$2.00 \times 090$ in his left eye. Dilated fundus exam showed mild swelling of both optic nerves. The patient reported blood glucose levels of 103-140. At a one-month follow-up, his best corrected visual acuity at a distance improved to $6 / 60$ in both the right and left eye through the new prescription. His cycloplegic retinoscopy did not show any change in myopia or astigmatism and the disk edema was resolved.

\section{Conclusion}

This case illustrates an unusual presentation of myopic shift post ABI. The patient's condition continued to deteriorate eventually taking his life. It remains unclear whether the myopia and astigmatism continued to increase or remained stable. Although, the cause of this change is not fully understood and needs further investigation, providing appropriate optical correction did improve the patient's quality-of-life.

Key words: tumours, myopia-treatment, brain injury.

Table 1: The Categories and Components of Acquired Brain Injury

\begin{tabular}{|l|l|}
\hline \multicolumn{2}{|c|}{ ACQUIRED BRAIN INJURY (ABI) } \\
\hline EXTERNAL INSULT - TBI & INTERNAL INSULT \\
\hline 1. Closed & 1. Cerebrovascular accidents (CVA) - i.e., stroke \\
2. Penetrating & 2. Brain surgery \\
\hline GLASGOW COMA SCALE & 3. Arteriovenous malformations (AVM) \\
\hline 1. Severe & 4. Brain tumours - malignant and benign \\
2. Moderate & 5. Vestibular dysfunctions \\
3. Mild & \\
\hline
\end{tabular}

neurological event, there is often an interruption to the neurological system which innervates the extraocular muscles controlling eye movement as well as the system that regulates focusing. Neuro-optometrists have identified a syndrome, the post trauma vision syndrome (PTVS), which includes visual symptoms and problems associated with trauma to the visual system (Table 2). ${ }^{1,3}$ Due to the similarities in the pathogenesis of TBI and stroke, there is considerable overlap in the ocular and visual symptoms. One such visual problem is a change in refractive error with an increase in myopia. Kowal identified a 19 per cent prevalence rate of pseudomyopia (58\% persisted) as one of common visual problems seen among 161 patients with head injury. ${ }^{6}$

London et al. suggest that many patients demonstrate a myopic shift in refractive error after TBI and refer to this myopic shift as "post-traumatic pseudomyopia".? Three reported courses have been suggested in non-presbyopic patients. Most commonly, the myopia resolves under cycloplegic conditions, secondly the shift is transient, and least commonly the myopia increases over time. This case report, although not due to a TBI, is an example of the least common subgroup. 
Table 2: Visual Sequelae and Symptoms of ABI

\begin{tabular}{|c|c|}
\hline 1. Visual field losses & $\begin{array}{l}\text { Central, congruous, and incongruous homonymous hemianopias and quadrantanopias, } \\
\text { altitudinal, neglect }\end{array}$ \\
\hline 2. Eye movement dysfunctions & Fixation, pursuit, saccade, nystagmus \\
\hline 3. Ocular muscle dysfunctions & Strabismus, anisocoria, lagophthalmos, ptosis \\
\hline 4. Binocular dysfunctions & Exophoria, convergence insufficiency, vertical phorias, fusional instabilities \\
\hline 5. Accommodative dysfunctions & Amplitude, flexibility, sustainability \\
\hline 6. Perceptual dysfunctions & $\begin{array}{l}\text { Contrast sensitivity, colour vision, body image, left-right discrimination, spatial } \\
\text { relationships, agnosias, "subjective visual disturbances." e.g., wavy and shimmering vision, } \\
\text { photosensitivity }\end{array}$ \\
\hline 7. Visually-involved vestibular dysfunctions & Vertigo, loss of balance, increased sensitivity to visual motion \\
\hline 8. Change of refractive error & Increased myopia \\
\hline 9. Symptoms & $\begin{array}{l}\text { Diplopia, blurred near vision, perceived movement of print, asthenopia, headaches, } \\
\text { photophobia }\end{array}$ \\
\hline
\end{tabular}

It is interesting to note that the progression of myopia has been reported in the younger population but is not the case in those over 40 years-of-age. Although the underlying mechanism is unclear, there is no known method to effectively halt the progression of the myopia over time. ${ }^{2}$

\section{Case Report}

\section{History}

The patient, a 63 year-old male, presented with a history of a right temporal lobe tumour excised 15 months prior to initial examination. A cerebral vascular accident (CVA or stroke) occurred post-surgically, causing hemiparesis to his left side. The patient is currently wheelchair bound. A right frontal shunt catheter was placed in the right lateral ventricle secondary to hydrocephalus. Ventriculomegaly was also reported on a CT scan. An MRI revealed extensive abnormal changes throughout the right frontal and temporal lobes most likely representing a combination of therapeutic effect and recurrent/residual tumor. Post-excision herniation of the brain through the craniectomy site occurred with the tumor extending into the splenium of the corpus callosum and the contralateral hemisphere.

Additional history included dexamethasone 4mg QD pre and post surgery which caused blood glucose levels to fluctuate between $5.72-22.2 \mathrm{mmol} / 1$. Medications included: Cartia, lisinopril, Toprol XL, prednisone, Reglan, and Temodar. The patient was receiving radiation and chemotherapy treatments to treat remnants of the tumour. His last eye exam in 2004, prior to the tumour, indicated a refractive error of $-2.50-1.25 \times 080$ in his right eye and $-3.00-0.75 \times 080$ in his left eye with visual acuity of $6 / 7.5$ in both the right and left eye at distance. Near visual acuity was not measured. Ocular health was unremarkable.

\section{Diagnostic data}

The patient presented to our clinic wearing a progressive lens and had a chief complaint of blurred vision in both eyes when viewing at a distance and near. No diplopia was reported. The following is a summary of our examination findings. His visual acuity, measured through his habitual correction of $-2.50-1.25 \times 080$ in his right eye and $-3.00-0.75 \times 080$ in his left eye with a near vision addition of +2.50 in both eyes, was $8 / 100(6 / 110)$ in both the right and left eye. His pupils were $5 \mathrm{~mm}$ in both eyes and equally reactive and responsive to light however, a relative afferent pupillary defect was present in the right eye. Cover test revealed a constant alternating esotropia of 15 prism diopters at distance and 18 prism diopters at near with a left hypotropia. A head tilt to the left and lack of general head control was noted as well as a bulge on the right temporal side 
of his head. Confrontation visual fields revealed a left homonymous hemianopsia. No spatial neglect was seen. Dry retinoscopy manifested less astigmatism in both eyes than his habitual correction: $-2.50-0.50 \times 180$ in his right eye and $-2.50-0.50 \times 180$ in his left eye. Cycloplegic retinoscopy, however, revealed a higher amount of both myopia and astigmatism in both eyes: $-5.25-2.50 \times 090$ in his right eye and -5.50-2.50×090 in his left eye. Anterior segment evaluation was unremarkable with the exception of mild blepharitis, meibomianitis, and mild cortical changes in both eyes. Posterior segment showed mild swelling of the optic nerves in the left eye more than right.

\section{Assessment}

The patient presented with an increased bilateral shift in myopia and astigmatism possibly due to the surgical removal of the tumour, subsequent stroke, and/or the medical intervention (i.e., radiation and chemotherapy to treat the tumour remnants). He also had a left homonymous hemianopsia with an associated left hemiparesis causing a loss of mobility, as well as a relative afferent pupillary defect in the right eye secondary to optic nerve head swelling (right eye $<$ left eye) from hydrocephalus.

\section{Management}

The patient was prescribed his full cycloplegic refraction -5.25$2.50 \times 090$ in his right eye and $-5.50-2.50 \times 090$ in his left eye for distance viewing. He was prescribed a separate pair of glasses for reading (-2.75-2.50×090 in both his right eye and left eye), rather than using a progressive or bifocal lens due to his poor head control. He was scheduled for shunt placement surgery to resolve the hydrocephalus. Since the patient was continuing with radiation, chemotherapy, as well as the aggressive medical management of the tumour remnants, it would be unclear whether the myopia and astigmatism will continue to increase or remain stable. The patient was scheduled to return to our clinic after wearing his new prescription for one month, after which he would be re-evaluated periodically over the following year. Vision therapy and low vision rehabilitation were discussed and would be addressed at a follow-up visit.

\section{Follow up evaluation}

(One month after initial evaluation)

During the follow-up examination, he was much more alert during than at his initial examination. Blood sugar had been monitored twice daily over the last month and was reported to be in the range of $5.72-22.2 \mathrm{mmol} / \mathrm{l}$. The patient's best corrected visual acuity at distance improved to $6 / 60$ with each eye individually and 6/38 with both eyes viewing. His near visual acuity through his near-vision prescription was $6 / 19$ with both eyes viewing. His cycloplegic retinoscopy was stable relative to the last visit and did not show any fluctuations in myopia or astigmatism. The disk edema had resolved in both eyes.

\section{Assessment}

The patient's wife reported that since he began wearing his distance prescription, he was able to see his family members much more clearly. His lateral balance had improved during physiotherapy and he had been holding his head upright on his own. He was also able to read his favourite magazines. Hence, a change in prescription and prescribing two separate pairs of glasses improved his quality-oflife. Visual acuity and visual function had both been improved such that the patient was now able to read magazines, watch television, and interact with his grandchildren without blurry vision.

\section{Management}

Our goal was to continue to monitor the patient periodically throughout the year. His condition continued to deteriorate causing him to lose speech, thus making communication more difficult. As changes in his condition occurred, there may have been secondary changes in his refractive error but due to his illness and frequent visits to the hospital, follow-up in our clinic was minimal. He was advised to continue using both pair of single vision glasses unless there was a change in prescription based on cycloplegic retinoscopy. His wife was advised to consider large print books if reading became difficult. No vision therapy or low vision rehabilitation was recommended as his condition remained 
unstable. The patient passed away in late November shortly after American Thanksgiving.

\section{Conclusion}

This case illustrates an unusual case of myopic shift post-ABI. Certain findings need to be considered for the increase in myopia. Firstly, the patient was on dexamethasone 4mg QD pre-and postsurgery causing blood glucose levels to fluctuate between 5.72-22.2 $\mathrm{mmol} / \mathrm{l}$. When he was seen for his eye evaluation, he was on prednisone. Effects of long-term use of systemic steroids include: increased blood sugar levels, blurred vision, elevated intraocular pressure with possible development of glaucoma, optic nerve damage, and posterior subcapsular cataract. ${ }^{8}$ Extra glucose in the hyperglycemic state causes an accumulation of sorbitol which disturbs the osmotic balance of the lens and plays a key role in cataract formation. Once sorbitol is in the lens, it draws water into the cells leading to swelling, and structural and chemical changes. This process may influence the refractive power of the lens, resulting in transient increases in myopia or cataracts because of the osmotic swelling of cortical fibres. ${ }^{9}$ In this patient's case, his uncontrolled blood glucose level along with his steroid induced diabetes, is a possible cause of the myopic shift. His anterior segment was remarkable for mild cortical changes, however, a posterior subcapsular cataract was not noted in either eye and blood sugar level, returned to

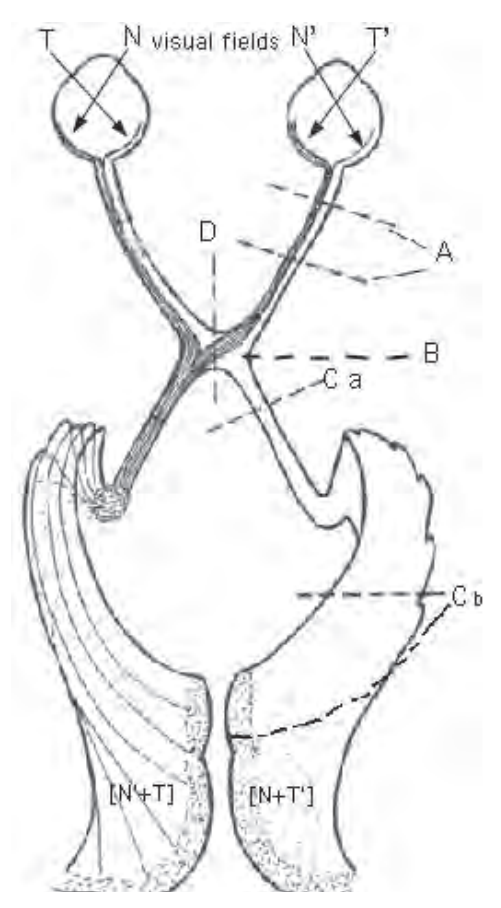

A. Total Blindness, right eye

B. Nasal hemianopsia of right eye

C. Left homonymous hemianopsia

a. with macular splitting

b. with either macular splitting or macular sparing

D. Bitemporal (heteronymous) hemianopsia
Figure 1 : Visual field defects

baseline once the corticosteroid dosage was reduced.

A second possible cause for the myopic shift would be an increase in axial length. Due to the patient's deteriorating condition, an A-scan was not done to rule out this possibility, however, the MRI did not show any remnant tumours in or around the orbit. In retrospect, it is unlikely that there was a tumour compressing each eye by the same amount resulting in an equal myopic shift in both eyes. Similarly, there was asymmetric optic nerve head swelling (right eye $<$ left eye) ruling it out as a cause for the myopic shift. The swelling could account for the reduction in visual acuity along with the relative afferent papillary defect.

The patient had a left homonymous hemianopsia with an associated left hemi-paresis and no spatial neglect. Homonymous hemianopias appear with lesions in the retrochiasmatic pathways. ${ }^{10}$ The more posterior the lesion is located in the optic pathways, the greater the congruity of defect. ${ }^{11}$ A homonymous hemianopsia can be seen with either macular sparing where the lesion occurs beyond the lateral geniculate body or macular splitting where the lesion can either be before or after the lateral geniculate body (Figure 1). ${ }^{12}$ As confrontational, not automated, visual fields were done do evaluate the patient's fields, it remains unclear if the defect was congruous and if the macula was spared or split. His relatively good visual acuity at near, however, could suggest macular sparing. Due to his 
left hemiparesis, is it probable the lesion was present along the right optic tract and cerebral peduncle. The MRI showed atrophy to the cerebral peduncle suggestive of wallerian degeneration or axonal degeneration from the insults to the right cerebral hemisphere.

Another possible cause for the myopic shift may be due to post-traumatic pseudomyopia. Pseudomyopia, an intermittent and temporary shift in the refractive error towards myopia, differs from true myopia as it develops over time and is the result of an accommodative spasm (AS) due to prolonged near work. AS is a triad of pseudomyopia, esodeviation, and pupillary constriction. It can either be organic in origin through the stimulation of the parasympathetic nervous system; or functional, through eye strain or fatigue of ocular systems. ${ }^{13}$ Voon et al. described a case in which AS was associated with dorsal midbrain syndrome with a blocked ventriculo-peritoneal shunt inserted for aqueductal stenosis. In this unusual case of pseudomyopia, an exodeviation was present without pupil constriction. ${ }^{14}$

Usually AS presents in young adults who have active accommodation or experience a change in their visual requirements such as preparing for an exam, or a change in occupation. Even when associated with organic disease, the patients reported in the literature have been under 57 years-of-age. Knapp et al. reported a patient that developed spasms of near reflex at the age of 86 years. She is to the authors' knowledge the oldest reported in the literature. In our patient's case, the triad of AS was present and most likely due to an organic cause rather than functional due to his reduced accommodative range.

The parasympathetic division of the oculomotor nerve is responsible for pupillary constriction and accommodation. ${ }^{15}$ London et al. have postulated a shift in myopia secondary to an irritative lesion that affects the accommodative portion of the parasympathetic third nerve subnucleus, resulting in ciliary body contraction, or possibly disinhibition of brainstem centres. ${ }^{7}$ Chan and Trobe, ${ }^{16}$ in a retrospective review of six patients with post-traumatic pseudomyopia, suggested that although it is rare, AS may present without other components of the near reflex. The AS may result from severe brainstem injury in young adults. Bohlmann et al. reported a patient with significant pseudomyopia nine years after her initial trauma. The resultant AS was suggested to be due to a possible mesencephalic lesion in the upper brainstem following trauma to the basilar skull. The authors felt it was important to recognize that some patients may experience a prolonged course of AS after significant head trauma and proposed that such cases may not be the result of a functional cause. ${ }^{17}$ The patient's MRI showed an abnormal signal extending on the right side down into the brainstem.

One can postulate that in our patient's case, the accommodative abnormalities could be caused by abnormalities of the midbrain or the oculomotor nerve. ${ }^{18}$ In cats, accommodation is mediated by a pathway from the lateral suprasylvian cortex bilaterally to the ocular motor nuclei. ${ }^{5}$ Stimulation of this area also causes convergence and miosis, but accommodation may be selectively activated. ${ }^{5}$ They also mention that although overactive accommodation appears to be uncommon in brain lesions, accommodative paresis is not. Among patients with lesions of the dorsal midbrain, accommodative paresis may alternate with accommodative spasm ${ }^{6}$ suggesting a linkage in accommodative excess and deficiency in brainstem damage. These spasms are more common in younger patients and can still be present after six years of topical atropine treatment. ${ }^{11}$ It is possible that the patient may have had an accommodative paresis resulting in his myopic shift.

The dysfunction and stress in the central and autonomic nervous systems causes imbalances in refractive and accommodative states of function as well as in ocular alignment. Leslie suggests that there is a pattern of PTVS with a moderate degree of myopia, and a moderate-to-severe degree of accommodative insufficiency. It is not accommodative spasm in the true sense, since there is excessive focus at distance but insufficient focus at near. In Leslie's experience, the cases studied are all long-term, chronic problems. The majority of these chronic cases studied show stable myopia and accommodative function over time. The mechanism behind this postulation is that brain trauma can disrupt a person's ability to 
access learned $\mathrm{z}$-axis sensorimotor control of accommodation in visual space. The system loses its ability to know and respond to changes in task distance. The accommodation system essentially localizes at its resting tonus (i.e., dark focus). Vision testing reveals myopia in the distance with an accommodative lag evident at near. Long-term, the system builds in this new learned space, unless the system is retrained at an early, plastic stage.

Treatment of AS often involves the use of plus lenses, accommodative exercises, or short-term cycloplegic usage. ${ }^{2}$ However, with post-traumatic pseudomyopia, the underlying mechanism is not clear and concurrent, causative treatment can vary between patients. It remains unclear as to which of the possible mechanisms could have been the cause of the myopic shift in this case.

For our patient, prescribing single vision minus lenses determined by cycloplegic refraction allowed for clearer distance vision. Prescribing single vision reading glasses as opposed to progressive addition lenses improved reading and function at near. According to London et al., if patients remain in pseudomyopic state beyond the first six-to-nine months posttrauma, they are recalcitrant to treatment and the full manifest minus lens correction is the only intervention that will relieve symptoms. ${ }^{7}$ Although, the cause of this change is not fully understood and needs further investigation, providing appropriate optical correction improved the patient's quality-oflife and should not be overlooked when managing patients with $\mathrm{ABI}$.

\section{References}

1. Optometrists Network. Problems Associated with Acquired Neurological Events. Allen H. Cohen. < http://www. braininjuries.org/brain_injury_double_ vision.html>

2. Torner JC, Shootman M. Epidemiology of closed head injury. In: Rizzo M, Tranel d, eds. Head Injury and Postconcussive Syndrome. New York: Churchill Livingstone, 1995: 19-46.

3. Suchoff IB, Ciuffreda KJ, Kapoor N. An Overview of Acquired Brain Injury and Optometric Implications. In: Suchoff IB, Ciuffreda KJ, Kapoor N, eds. Visual and vestibular consequences of acquired brain injury. Santa Ana, Calif:: Optometric Extension Program, 2001:1-9.

4. Hibbard MR, Gordon WA, Kenner B. The Neuropsychological Evaluation: A Pathway to Understanding the Sequelae of Brain Injury. In: Suchoff IB, Ciuffreda KJ, Kapoor N, eds. Visual and vestibular consequences of acquired brain injury. Santa Ana, Calif.: Optometric Extension Program, 2001: 32-47

5. Ciuffreda $\mathrm{KJ}$ et al. Oculomotor consequences of acquired brain injury. In: Suchoff IB, Ciuffreda KJ, Kapoor N, eds. Visual and vestibular consequences of acquired brain injury. Santa Ana, Calif.: Optometric Extension Program, 2001:77.

6. L Kowal FRACO (1992) Ophthalmic manifestations of head injury Australian and New Zealand Journal of Ophthalmology 20 (1) , 35-40.

7. London R, Wick B, Kirschen D. Posttraumatic pseudomyopia. Optometry 2003;74:111-20.

8. Bartlett J.D. and Jaanus S.D., Clinical Ocular Pharmacology 4th ed. Woburn: Butterworth-Heinemann. (2001)

9. Optometric Management. Preventing Diabetic Cataracts Naturally. Jospeh Freedman. http:// www.optometric.com/article. aspx?article $=\& l o c=$ articles $\backslash 2001 \backslash$ june $\backslash 0601086 . h t m$

10. Huber A. Homonymous Hemianopsia. Neurto-opthalmology 1993; 12:351-266.

11. Brazis P. W., Masdeu J.C., and Biller Jose. Localization in Clinical Neurology 4th ed. Philadelphia: Lippincott Williams \& Wilkins, 2001.

12. Carpenter, M.B. and Sutin, J. Human Neuroanatomy, Williams and Wilkins, Baltimore and London, 1983, p. 544.

13. Rutstein RP, Marsh-Tootle W. Acquired unilateral visual loss attributed to an accommodative spasm. Optom Vis Sci 2001;78:492-5.

14. Voon LW, Goh KY, Lim TH, et al. Pseudomyopia in a patient with blocked ventriculo-peritoneal shunt--a case report. Ann Acad Med Singapore 1997;26:229-31.

15. Crossman, A.R., and Neary, D. Neuroanatomy 2nd ed An Illustrated Colour Text. Edinburgh: Harcourt Publishers Limited, 2000.

16. Chan RV, Trobe JD. Spasm of accommodation associated with closed head trauma. J Neuroophthalmol 2002;22:15-7.

17. Bohlmann BJ, France TD. Persistent accommodative spasm nine years after head trauma. J Clin Neuroophthalmol 1987;7:129-34.

18. Ohtsuka K, Maekawa H, Takeda M, et al. Accommodation and convergence insufficiency with left middle cerebral artery occlusion. Am J Ophthalmol 1988; 106:60-4.

19. Padula WV, Shapiro JB. Post-Trauma Vision Syndrome Caused by Head Injury. In:Padula WV, eds. NeuroOptometric Rehabilitation. Santa Ana, Calif:: Optometric Extension Program, 2000:179-193.

20. The Optometric Extension Program Foundation. Post trauma vision syndrome: myopia and accommodative insufficiency. Steve Leslie. <http://www. oepf.org/Docs/ICBO2006Leslie.pdf> 